
upf. $\begin{array}{ll}\text { Universitat } & \text { Department } \\ \text { Pompeu Fabra } & \text { of Economics and Business }\end{array}$ Barcelona

Economics Working Paper Series

Working Paper No. 1570

\title{
How should we model property? Thinking with my critics
}

\author{
Benito Arruñada
}

May 2017 


\title{
How Should We Model Property? Thinking with My Critics
}

\author{
Benito Arruñada* \\ Pompeu Fabra University and Barcelona GSE
}

\begin{abstract}
Inspired by comments made by Allen (2017), Lueck (2017), Ménard (2017) and Smith (2017), this response clarifies and deepens the analysis in Arruñada (2017a). Its main argument is that to deal with the complexity of property we must abstract secondary elements, such as the physical dimensions of some types of assets, and focus on the interaction between transactions. This sequential-exchange framework captures the main problem of property in the current environment of impersonal markets. It also provides criteria to compare private and public ordering, as well as to organize public solutions that enable new forms of private ordering. The analysis applies the lessons in Coase (1960) to property by not only comparing realities but also maintaining his separate treatment of the definition of property rights and transaction costs. However, it replaces his contractual, single-exchange, framework for one in which contracts interact, causing exchange externalities.
\end{abstract}

Keywords: property rights, externalities, enforcement, transaction costs, public ordering, private ordering, impersonal exchange.

JEL: D23, K11, K12, G38, H41, O17, P48.

*Email: benito.arrunada@upf.edu. Thanks to Douglas W. Allen, Mircea Epure, Dean Lueck, Claude Ménard, Nicolás Nogueroles, Cándido Paz-Ares, Henry E. Smith and Giorgio Zanarone for their comments. This work received support from the Spanish Government through grant ECO2014-57131-R. 


\section{Introduction}

I wish to thank Doug Allen (2017), Dean Lueck (2017), Claude Ménard (2017) and Henry Smith (2017) for their valuable insights and criticisms. I feel honored to receive comments from such an extraordinary group of scholars, and these pages try to correspond to their effort in order to enlighten our search for a better understanding of property institutions.

The main thread in most of my response is the question of how we should conceptualize property. It unfolds in three directions: what type of asset should we pay attention to, what degree of analytic abstraction is the most promising, and, in particular, which simplifying assumptions are the most useful. For each of these three points, I will first explain my argument and then show how some of my critics’ positions can be made more effective by adopting a sequential-exchange view and applying the main methodological mandate from

Coase (1960), namely, analyzing real alternatives. This requires examining the structure of property law, instead of imagining a contractual fantasy of “property” rights. In this vein, my paper is not a critique on Coase (1960) but on the insistence of some of his followers on focusing as a reference on zero-transaction costs and maintaining a single-exchange framework that I deem inadequate for understanding the institutions of property markets. I conclude with a brief comment on how sequential exchange has been applied to clarify some organizational issues, including the role of public ordering in enabling more advanced forms of private ordering. 


\section{The error of confusing sequential exchange with land}

Several of my critics prefer to focus their comments on land. This makes the analysis seem simpler but in fact obscures the origin of transaction costs. It not only minimizes the problem that sequential exchange poses to markets, law and economics but, by misidentifying the source of transaction costs, emphasizes minor aspects, such as physical complexity. This results in misguided conclusions.

For instance, Dean Lueck (2017) claims that "the real source of the problem in property is that assets (parcels of land) are complex and physically connected.” I disagree because, first, sequential exchange is not caused by the particular characteristics of land and therefore limited to land or even property. Instead, it is a major issue in many other areas, such as agency, commercial and corporate law, organized exchanges, financial instruments, and even family law (Arruñada 2010b, 2012, 2016; Arruñada and Manzanares 2016). Take, for instance, a pure agency context. If, when contracting with $T$, $P$ 's agent $A$ commits $P$, $P$ 's commitment is valuable because of the added guarantee offered by $P$. Durable assets supply an obvious example but are not essential for the problem of sequential exchange: without durable assets, similar allocation problems remain in terms of priority (between, for instance, the several types of P's creditors). Therefore, most sequential exchanges are unrelated to land or even durable property.

Moreover, in itself, physical complexity is easy to handle contractually. It is true that "the use of the various attributes of the land affects the other attributes". But, contrary to what Lueck asserts, if, for instance, a farmer damages a stream of underground water, this 
incident poses a purely Coasean case of use externalities that can be handled by contractual means, bilaterally and without requiring enhanced impartiality (with two or more parties, but in a bilateral relation and with a single contract). The nature of the problem is easier to understand if we recognize that different attributes of a supposedly unique and complex asset can be fruitfully conceptualized and legally defined as different assets, this being a major reason why a bundle-of-rights view is useful for analyzing the structure of property. Instead, focusing on land may lead analysts to take land parcels, instead of rights, as the most relevant units of analysis, when for many purposes they are not, from either a legal or an economic perspective. Take, for instance, the difficulties for contracting a second mortgage: the problem has less to do with land than with the prioritizing of claims, including possible prior mortgages.

For the problem at hand, what matters most is the structure of its relevant complexity. I submit that, within the private law sphere, it is the presence of hidden contractual effects that causes the type of information asymmetry that makes it necessary to implement property institutions (mainly, adjudication rules and their organizational apparatus, including enhanced impartiality). Note, first, that it is not only the hidden attribute of the effects but the presence of contractual interaction that imposes tougher demands on the institutional framework. Hidden externalities which only affect two parties (such as the potentially hidden use externalities mentioned by Lueck) can be handled by a bilateral contractual framework. More to the point: the institutions required to solve them (e.g., measuring and pricing mechanisms) do not need a higher standard of impartiality to protect third parties, because such third parties simply do not exist. Private-ordering arrangements 
therefore have better prospects to succeed, as suggested by the successful cases in the literature on common resources (Ostrom 1990), which can be described as hybrid throughout the private-public dimension.

The problem is intrinsically harder when it is previous contracts that cause nonobservable consequences, because then third parties are involved. To be clear, most contracts also cause observable consequences, which can then be used by the law to establish rules for subsequent contracts. Such rules are related to possession in the area of property (for immovables but mainly for movables in commercial law) and to nonpossessory “appearance” in other areas (perhaps the most prominent example being the role of apparent authority in an agency context ${ }^{1}$ ). What causes a different type of information asymmetry, making transactions harder and the single-exchange framework insufficient, are contracts that affect subsequent transactions but lack observable consequences and therefore produce hidden contractual effects. Secure lending is an obvious example but the same situation arises with ownership and many rights connected to agency relations. ${ }^{2}$

This legal-complexity argument gives a better explanation of the demarcation and servitudes cases with which Lueck tries to support his argument.

\footnotetext{
${ }^{1}$ When a reasonable third party would understand that an agent had authority to act, the principal is usually bound by the agent's actions, even when the agent has no actual authority.

2 This argument also applies to the "notice-giving devices and traffic rules of priority" mentioned by Smith. Note that such devices and rules become more effective when only a single in rem right is enforced in an asset, because this allows possession or its delivery to fully perform the titling function. This points, again, to the relevance of the bundle-of-rights conception.
} 
With respect to boundary demarcation, Lueck’s interpretation of the difference between the "rectangular survey" (RS) and "metes and bounds" (MB) is misguided, as these are only alternative techniques for physical demarcation (i.e., for identifying parcels and surveying their boundaries) and both can be performed with or without legal demarcation of boundaries (i.e., reaching a social agreement with neighbors, often via judicial or quasijudicial procedures [Arruñada 2017c]). The differences observed by Libecap and Lueck (2011) must not be attributed only to the different techniques for physical demarcation but also to the fact that, in the historical episode that they analyze, these techniques were applied with and without legal demarcation: boundaries in RS areas were drawn by an RS and were also purged of conflicting claims, but there was no such legal purge in MB areas. As Libecap and Lueck explain, not only were both sets of parcels physically demarcated in different ways but they were also “claimed”-i.e., legally demarcated—differently (Libecap and Lueck 2011: 433). Therefore, their work in fact tests two joint hypotheses (physical and legal demarcation). Some of their empirical findings even suggest that it is not the difference in physical demarcation but in legal demarcation that caused the observed differential effects. The most obvious point here is that the plots under MB, which were privately demarcated with “no external constraint”, are more likely to overlap, which means that prices in the two areas may refer to different surface units; but some other findings also support the legal demarcation hypothesis. In particular, Libecap and Lueck observe value differences in farmland but not in urban land, whose boundaries are usually more precise. Legal demarcation is also consistent with their finding that most $19^{\text {th }}$ century litigation in MB areas is not related either to boundaries (1.46 for 1,000 parcels, about 4 times more than in rectangular survey areas) or to the validity of the survey $(2.48 \%$, 31 
times more) but to the validity of the entry/patent (8.61\%, 33 times more). Therefore, legal demarcation seems to have been more important than physical demarcation as a driver of litigation and, possibly, of transaction costs and land value.

With respect to servitudes, Dnes and Lueck (2009) model them as an exogenous incident. However, in fact, servitudes are created at some point by an originative transaction. And the problem with enforcing servitudes in rem arises not when they are "hard to measure and enforce” but when they are hard to observe and, as a consequence, they may well remain secret to all potential buyers of rights in that particular type of asset. Even if servitudes—e.g., a right of way—are often considered non-possessory rights because the holder of the servitude is not in possession of the land, they must be exercised, which requires temporary possession and, crucially, provides some sort of possessory evidence, such as the footprints marking a path in a right of way. ${ }^{3}$

\section{The need to focus on sequential exchange for understanding the institutions of impersonal markets}

Henry Smith (2017) considers sequential exchange as a genuine problem but contends that "it is part of a larger inadequacy in the economic analysis of property rights: property institutions have to manage complexity stemming from many kinds of interactions”. I agree

\footnotetext{
${ }^{3}$ I discussed the titling role of possession in Arruñada (2015).
} 
that the role of sequential exchange is more obvious for impersonal property markets than for property as a whole, and establishing its general importance remains an open question.

However, this poses two familiar methodological questions. First, what is the proper degree of abstraction for a given problem? Choices about the optimal level of abstraction and the pertinent simplifying assumptions depend on the problem under analysis, and must be judged by their predictive power. My concern is that the single-exchange (bilateral contracting) assumption in Coase (1960) has been misapplied by some of his followers, causing an analytical deficit that has ended up supporting policy mistakes. In contrast, I defend assuming sequential exchange to improve our understanding of the key institutions of property markets. Considering the additional dimensions pointed out by Smith would undoubtedly enrich the analysis, but it would also reduce its tractability, while not affecting the key points I wish to make.

Second, Smith’s criticism raises a broader issue for the analysis of property institutions, related to environmental adaptation. As different social and economic environments pose different problems, one may also wonder what is the most serious problem for property today. In this vein, even if "interactions can be—-but need not be—contractual”, contractual interactions are likely the key element in the functioning of impersonal markets and in the performance of their institutions. Conversely, non-contractual interactions and other dimensions of property complexity are of lesser importance for modern economies. It is not by chance that potential transactors play the major role in the optimal standardization of property analyzed in Merrill and Smith (2000: 26-27, 31-33), Smith (2011: 157-60), 
Merrill and Smith (2011: S91), or in some of the modularity examples in Smith’s comment. ${ }^{4}$

Moreover, in more practical terms, to what extent do the non-contractual interactions emphasized by Smith challenge the conclusions obtained in my analysis, based on contractual interactions? This question surely requires further research, but, in principle, it is not obvious that at least the key requirement of enhanced impartiality, with its limiting effect on private ordering, is affected. On the contrary, non-contractual interactions (for example, a theft case) also require enforcers to be impartial to all. This is because sequential exchange is less voluntary than it might seem. It is true that sequential exchanges are composed of at least two voluntary bilateral interactions (i.e., principal $P$ contracts with agent $A$, who then contracts with third party $T$ ), but only agents act voluntarily in both, exercising their choice. It is an involuntary element that characterizes the interactions between principals and third parties. Balancing the vulnerability inherent in the consequent lack of choice requires enhanced impartiality, makes unassisted private ordering less effective and, as explained in section 5, enhances the enabling role of public ordering, with little risk of "overestimate[ing] the case against private ordering". To this extent, my

${ }^{4}$ Furthermore, at least some non-contractual interactions can also be analyzed in a sequential-exchange framework. Theft, for instance, is treated by the law in a sequentialexchange framework when it determines the enforcement of property rules on filing of a complaint by the owner. In general, we may gain by conceptualizing "transactions" broadly, to include not only explicit consensual agreements but also implicit nonconsensual interactions. Similarly, Ménard is right that "not all transactions are sequential and many contracts are bilateral" but in most cases single-exchange transactions take place within broader sequential exchanges. In short, sequential exchange is composed of single exchanges, a feature that provides the structural link between contract and property. 
conclusions are unlikely to change; and, if this conjecture is confirmed, the abstracting strategy for explaining complexity would again prove its power.

In contrast to Smith’s view that "the larger problem of complexity allows us to set sequential exchange in its proper context”, I fear that, when we aim for comprehensiveness, the analysis of complex realities such as property may become less effective, at least in problem-solving. This search for comprehensive explanations detached from problemsolving may also lead us to inadvertently focus on secondary aspects and even cause occasional confusion. For example, the emphasis on exclusion—a general duty of noninterference —as the main structural feature of property sidelines rights which at most include only potential exclusion (such as, e.g., mortgages) but play a major role in hindering impersonal exchange; and may keep the analysis too focused on a static view of property, more suitable for traditional societies with little trade. Similarly, the emphasis on customization may obscure the fact that standardized but hidden charges would still preclude impersonal trade. More conjecturally, since they are detached from the economic context, holistic theories may even be more likely to rely on anachronic rules, such as nemo $d a t$, as the starting point for exploring property, ${ }^{5}$ even though the vast majority of today's transactions are governed by some variant of the good-faith purchaser rule. This suggests a sort of evolutionary maladaptation that favors old legal institutions, suitable for a static economy with, at most, personal exchange (Arruñada 2012: 114-18).

${ }^{5}$ According to the legal rule of "Nemo dat quod non habet" (literally meaning "Nobody gives what does not have"), ownership title cannot be acquired from a person who is not the owner. Note that today this rule does not apply, for instance, to most commercial transactions. 
Given their lesser precision, more comprehensive theories may also cause occasional confusion. I wonder if this might be the case with "thinghood", to the extent that this concept seems to oscillate between the physical and the legal world. Its physical roots seem to be behind Smith's assertion that “[w]hat Libecap and Lueck show is that the institution of the rectangular survey [RS] allowed for the definition of legal things.” I would submit that this is, to say the least, inaccurate, as explained above, because, for the case studied by Libecap and Lueck (2011), we do not even know if RS made legal demarcation easier or not, and at what cost. ${ }^{6}$

Conversely, legal thinghood is not easy to distinguish from modularity. Both exchange and modularity can be conceived as two sides of the same coin, with modularity being the institutionally-enabled solution to the sequential-exchange problem. What these institutions produce are legal commodities—modules—-to mainly allow impersonal interactions. Therefore, a transactional view is implicit in the modularity argument. This obviously includes negotiable instruments but also trust law when contemplated from an assetpartitioning perspective, in which sequential exchange also plays a very prominent role (Hansmann and Mattei 1998). ${ }^{7}$

\footnotetext{
${ }^{6}$ RS was simply used in combination with such a "definition of legal things" (what I above called legal demarcation). Given that Libecap and Lueck could only compare RS-withlegal-demarcation against MB-without-legal-demarcation, their findings tell us nothing about the differential effects of RS or MB, or of their interaction with legal demarcation. (To be informative on the latter, they would have needed data on cases of RS-withoutlegal-demarcation and cases of MB-with-legal-demarcation, and such cases were unavailable.

${ }^{7}$ By the way, trust law provides an example of the above-mentioned, anachronic focus on personal exchange, common in legal scholarship, given that "academic commentary and
} 


\section{The difficulty of taming legal horses}

Several comments share an imprecise interpretation of my paper as a critique of Coase (1960). However, I do not criticize Coase, because relying on a contractual framework is pertinent for analyzing his problem and for many other issues, as shown by its fruitful application to an enormous variety of realities. My critique is limited to the pretense of studying property using a contractual single-exchange framework, a mistake that contradicts the main methodological lesson in Coase (1960): his emphasis on analyzing real alternatives, a task that should start here by examining the structure of property law, instead of imagining a contractual fantasy of "property" rights. Coase repeatedly criticized economists for not paying enough attention to reality. On one special occasion, he declared: "Economists, by and large, do not study the workings of the actual economic system. They theorize about it. As Ely Devons, an English economist, once said at a meeting, 'If economists wished to study the horse, they wouldn't go and look at horses. They'd sit in their studies and say to themselves, "What would I do if I were a horse?” , ', (Coase 1999). Even some of Coase's followers may once in a while be tempted to imagine "legal horses" instead of studying real ones.

But we should not hide our theorizing behind Coase, instead of following his main lesson. Neither should we worship Coase to the point of believing that his original

law school curricula continue to focus on the private trust in its historical role as a device for intrafamily wealth transfers. Today, however, that role is relatively trivial. Vastly more important is the enormous - though commonly neglected —role that private trusts have come to play in the American capital markets” (Hansmann and Mattei 1998: 436). 
framework (or a distorted version, such as, arguably, an all-inclusive conception of transaction costs) does not need any adaptation when applied to different problems. I do not consider that "to deal with these issues [sequential exchange,] relying on Coase (1960) is inadequate, even misleading” (Ménard 2017). Not at all. What I consider inadequate is to rely on the bilateral-contracting assumption when trying to study the institutions of property markets. What creates confusion is that Coase (1960) has been misused to support a theory of so-called property that is not about property and often is not Coasean. It is not about property because it remains purely contractual. And it is not Coasean when it limits itself to imagining instead of studying reality.

This clashes with Doug Allen's critique (2017) and, in particular, with his advice to conflate property rights and transaction costs, so that the latter become an all-inclusive concept. ${ }^{8}$ This is awkward if we consider that a conflated view would be strange to most economic analyses as well as to Coase (1960), who, contrary to Allen's claims, repeatedly defines transaction costs as the costs of trading in the market, and keeps them clearly separated from property rights. ${ }^{9}$

${ }^{8}$ Allen laments that my message will be ignored because of both logical and semantic flaws. There might be logical missteps in my analysis but he fails to point them out. Therefore, I can only respond to his seemingly semantic critique.

${ }^{9}$ E.g., "when the damaging business has to pay for all damage caused and the pricing system works smoothly (strictly this means that the operation of a pricing system is without cost)" (Coase 1960:2); "if the cattle-raiser is liable for damage caused and the pricing system works smoothly" (p. 5); or in Section IV, when he then turns "to the case in which, although the pricing system is assumed to work smoothly (that is, costlessly), the damaging business is not liable for any of the damage which it causes.” (p. 6). In all of these cases the two assumptions about zero transaction costs and clear allocation of property rights are stated separately. Moreover, when defining transaction costs, Coase does not include 
Moreover, in his entry on transaction costs in the Elgar Encyclopedia of Law and Economics, Allen himself concluded that "which definition [of transaction cost ] is useful depends on what question is being examined” (Allen 2000: 913). Applying this sound contextual advice, it is clear that a conflated view of transaction costs would be the wrong choice when aiming to identify the structure of transaction costs that makes property institutions necessary. It would likely miss the main conflict between in rem enforcement and the cost of trading, which is the rationale for property institutions, and would therefore lead to misguided conclusions. One may even conjecture that the conceptual conflation of property rights and transaction costs has been a major reason why many transaction cost analyses have focused on contracts and paid little attention to the main property institutions, focusing at most on the fringe elements of property and ignoring property (in rem) rights, despite their central role in property markets.

This latter risk is exemplified by Allen's comment, which makes three distinct mistakes when trying to apply his argument. First, Allen asserts that "problems also arise over forgotten sequential claims. Indeed, the problems can arise even when there is no

among them the definition of rights. When in section VI he starts considering positive transaction costs, Coase makes it clear that what he has in mind are the "costs involved in carrying out market transactions". He says: "In order to carry out a market transaction it is necessary to discover who it is that one wishes to deal with, to inform people that one wishes to deal and on what terms, to conduct negotiations leading up to a bargain, to draw up the contract, to undertake the inspection needed to make sure that the terms of the contract are being observed, and so on.” (p. 15). Therefore, he includes search, matching, negotiation, contracting and enforcing but excludes the definition of property rights. Understandably, the distinction was necessary for Coase to discuss the scope of judicial and statutory action in Section VII, a section that deals with "The legal delimitation of rights and the economic problem" where Coase explains how, under positive transaction costs, courts and statutes can improve on parties' contractual action. 
sequence!”. With respect to "forgotten claims", these should pose little difficulty, given the absence of information asymmetry. And as to Allen's claim about the lack of sequence, this is hard to understand, because the whole analysis of sequential exchange is based on the interaction between contracts; and for contracts to interact they must necessarily be in a legal sequence. Second, Allen conceives an in rem right as "one that is more complete than an in personam right” when the difference between rights in rem and in personam is not one of completion (both grant the same use claims on the same asset in the same contingencies) but one of enforcement-i.e., given any material content for the right and at any level of completeness, the remedies triggered by the same contingencies are drastically different for an in rem or an in personam right. Third, Allen also oddly claims that partial rights on assets are in personam ("If the property rights are all owned, but the ownership of the various attributes are spread across many individuals... we might say [they are] in personam"). This makes no sense in the real world because it would mean that two persons holding rights on the same asset—for instance, the owner and the mortgagee—-would both hold in personam rights. These errors only confirm the conjecture that there is an important lesson in Allen's position: it shows how both using zero-transaction-costs scenarios as a reference and assuming a single-exchange perspective hinder the understanding of real institutions - in this case, they seem to make it impossible to keep in mind a consistent concept of rights in rem.

However, as above, the most general and most serious issue is which concepts and assumptions should be used to better understand the structure of positive transaction costs in the real world, aiming for a more operational diagnosis than "positive transaction costs". 
Coase hypothesized zero transaction costs not to explain reality but to make the methodological point that economists should focus on studying positive transaction costs. It is well known that mainstream economists have paid only selective attention to Coase's request. What is less well known is that some of Coase's followers also disobey him when they insist on using imagined situations of zero transaction costs as the reference point for their analysis. Apparently, they do not realize that eternally replicating the Coasean comparison of zero and positive transaction costs repeats a point first made in 1960. It is not only unnecessary but causes confusion and precludes the important task of understanding the structure of transaction costs.

This also happens with Allen's comments, which recurrently confront situations of zero and positive transaction costs. These may explain some of his weirdest assertions. For instance, despite the fact that my analysis does not even use zero-transaction-costs as a reference, Allen grossly mischaracterizes it when he writes that "[b]y assuming that the 'trading costs' are zero and then calling them 'transaction costs', Arruñada is drawn to infer there is something special about 'sequential exchange' in and of itself, but this is not true”. Revealingly, Allen contradicts himself in the next paragraph, to agree with me when saying that "when transaction costs are positive...., given the problems of sequential exchange and secrecy, we should expect a complex type of institutional solution that is the appropriate choice in the given context.”

I could not agree more on the last point, but we probably need analyses that, when suggesting solutions, are capable of rendering some more detail than "a complex type of institution”. 


\section{The enabling role of public ordering}

Claude Ménard (2017) also demands greater detail. In particular, even if he is sympathetic to the idea of creating "flexible public-private interfaces with the bureaucracies in charge of the public core of formalization services while allowing the free market to organize a multifaceted intermediate sector”, Ménard requests more detail about, among other aspects, the "exact combination of public and private elements.... the enforcement.... [and] the potential role of technological changes”.

I would submit that the sequential-exchange framework helps to distinguish the enabling and regulatory roles of public ordering (as they are mainly connected, respectively, to exchange and use externalities), and provides an operational way of identifying the comparative advantage, organizational constraints and viable hybridization of private- and public-ordering solutions. In addition to the cases summarized in the paper, sequential exchange has contributed along these lines in analyzing the organization of notaries public (Arruñada 1996, 2007), title insurers (Arruñada 2002), recorders for Internet domains (Arruñada 2003: 427), one-stop shops for business formalization (Arruñada 2010a), company registries (Arruñada 2010b, Arruñada and Manzanares 2016), providers of business information (Arruñada 2011), real and intellectual property registers (Arruñada and Hansen 2015), and the consequences of technological change, as recently epitomized by blockchain (Arruñada 2017b).

A common feature of most of the public solutions analyzed in these works is that-far from precluding - they enable private-ordering solutions. To this extent, the analysis of 
sequential exchange not only clarifies the puzzling ambiguity and elasticity in what is "public" in property but also prevents the risk, also envisioned by Smith, of a "too-quick assumption that private ordering does not work”. Simply put, this type of public ordering makes more developed forms of private ordering possible. The most obvious example is perhaps the corporation. As argued in Arruñada (2010b), it was company registration that allowed entrepreneurs to overcome the huge difficulties they faced when they formed unincorporated companies by purely contractual means, as described by Harris (2000). Registered companies are still mostly the product of private ordering; however, they face much lower transaction costs than unincorporated companies because they enjoy the support of a public-ordering institution designed with a sequential-exchange view. In contrast, analyses that assume single exchange or focus on the static problems of property fail to provide any basis for identifying when public solutions are required to enable impersonal property markets. In my view, the fact that, as asserted by Smith, "public ordering... is not necessary for more of the time" is unremarkable. Such public ordering is needed only for a limited but extensive set of interactions: those with hidden contractual effects, as explained in section 2 .

Certainly, more work remains to be done, but sequential exchange can even satisfy our common demand for detail in an unexpected corner, the marriage "market”. Ménard finds weird my definition of a "public solution as one that 'involves strangers to the intended transaction'”. Apart from the fact that there seems to be a misunderstanding here, because what Ménard calls a stranger to the transaction is in fact partial to one of the transaction parties, even Ménard's marriage example is on my side, as marriage is in essence a 
property transaction: as I argued elsewhere (Arruñada 2012: 238-39, n. 14), traditional marriage contracting poses problems and relies on solutions similar to those found in real property. Thus, incentives to invest are affected by information asymmetries caused by possible hidden claims and alternative adjudication rules, related to the multiple conflicting claims held by intended spouses, children, and families on spouses themselves and their wealth. As with real property, contracting also takes place in two steps, with the private engagement producing legal consequences only for the parties. It is the public wedding that commits everybody, thanks to its reliance on an array of devices, including registries of marital status, publicity by banns and processions, the presence of priests acting as notaries, registrars, and gatekeepers, and even a purge of previous claims ("speak now or forever hold your peace"). It is this publicity which allowed the law to grant priority to rights arising from formal, nonclandestine marriage, thus providing strong incentives to invest. There has been a recent evolution toward "contract” marriage, but without any change, for instance, in the treatment of second marriages, which are still the equivalent of double sales of land.

\section{Concluding remarks}

In response to the excellent comments by Allen, Lueck, Ménard and Smith to Arruñada (2017a), I made here several methodological points as to how we should best study the institutions of property markets. This task requires replacing the bilateral contractual conception in which two parties interact through a single contract with a sequential- 
exchange assumption in which more than two parties interact through at least two contracts. However, two key positions in Coase (1960) are perfectly suitable to the study of property markets, namely, considering the definition of property rights separately from transaction costs and focusing on the comparative analysis of real institutions. Moreover, this sequential-exchange view is particularly fruitful for studying modern impersonal markets and the interface between public and private-ordering, with public ordering acting as an enabler of more developed private-ordering solutions.

\section{References}

Allen, Douglas W. (2000), 'Transaction Costs', in Boudewijn Bouckaert and Gerrit De Geest, eds., The Encyclopedia of Law and Economics, vol. 1, Cheltenham UK: Edward Elgar, 893-926.

Allen, Douglas (2017), 'Property as Sequential Exchange: Definition and Language Issues’, Journal of Institutional Economics, published online. DOI: 10.1017/S1744137417000091.

Arruñada, Benito (1996), ‘The Economics of Notaries', European Journal of Law and Economics, 3(1), 5-37.

Arruñada, Benito (2002), 'A Transaction Cost View of Title Insurance and its Role in Different Legal Systems’, The Geneva Papers on Risk and Insurance, 27(4), 582-601.

Arruñada, Benito (2003), 'Property Enforcement as Organized Consent', Journal of Law, Economics, and Organization, 19(2), 401-44.

Arruñada, Benito (2007), 'Market and Institutional Determinants in the Regulation of Conveyancers', European Journal of Law and Economics, 23(2), 93-116.

Arruñada, Benito (2010a), Formalización de empresas: Costes frente a eficiencia institucional, Thomson Reuters, Cizur Menor.

Arruñada, Benito (2010b), 'Institutional Support of the Firm: A Theory of Business Registries', The Journal of Legal Analysis, 2(2), 525-76.

Arruñada, Benito (2011), 'Mandatory Accounting Disclosure by Small Private Companies' European Journal of Law and Economics, 32(3), 377-413. 
Arruñada, Benito (2012), Institutional Foundations of Impersonal Exchange: Theory and Policy of Contractual Registries, Chicago: University of Chicago Press.

Arruñada, Benito (2015), 'The Titling Role of Possession', in Yun-chien Chang, ed., The Law and Economics of Possession, Cambridge: Cambridge University Press, 207-33.

Arruñada, Benito (2016), 'How Rome Enabled Impersonal Markets', Explorations in Economic History, 61, 68-84.

Arruñada, Benito (2017a), 'Property as Sequential Exchange: The Forgotten Limits of Private Contract', Journal of Institutional Economics, published online. DOI: 10.1017/S1744137416000473.

Arruñada, Benito (2017b), 'Blockchain’s Struggle to Deliver Impersonal Exchange', Minnesota Journal of Law, Science \& Technology, forthcoming.

Arruñada, Benito (2017c), 'The Economics of Land Demarcation', contribution to the $18^{\text {th }}$ Annual World Bank Conference on Land and Poverty, Washington DC, March 21.

Arruñada, Benito, and Carlos A. Manzanares (2016), 'The Tradeoff Between Ex Ante and Ex Post Transaction Costs: Evidence from Legal Opinions’, Berkeley Business Law Journal 13(1), 217-55.

Arruñada, Benito, and Stephen Hansen (2015), 'Organizing Public Good Provision: Lessons from Managerial Accounting', International Review of Law and Economics, 42, 185-91.

Coase, Ronald H. (1960), 'The Problem of Social Cost', Journal of Law and Economics, 3(1), 1-44.

Coase, Ronald H. (1999), 'Speech to ISNIE: The Task of the Society', Opening Address to the Annual Conference of the International Society of New Institutional Economics, Washington DC, September 17, available at https://www.coase.org/coasespeech.htm (accessed October 10, 2014).

Dnes, Antony, and Dean Lueck (2009), 'Asymmetric Information and the Law of Servitudes Governing Land', Journal of Legal Studies, 38(1), 89-120

Hansmann, Henry, and Ugo Mattei (1998), 'The Functions of Trust Law: A Comparative Legal and Economic Analysis’, New York University Law Review, 73, 434-79.

Harris, Ron (2000), Industrializing English Law: Entrepreneurship and Business Organization, 1720-1844, Cambridge: Cambridge University Press.

Libecap, Gary D., and Dean Lueck (2011), 'The Demarcation of Land and the Role of Coordinating Property Institutions', Journal of Political Economy 119(3): 426-67.

Lueck, Dean (2017), 'Property Institutions and the Limits of Coase', Journal of Institutional Economics, published online. DOI: 10.1017/S1744137417000194.

Lueck, Dean, and Thomas J. Miceli (2007), 'Property Law', in A. Mitchell Polinsky and Steven Shavell, eds., Handbook of Law and Economics, vol. 1. Amsterdam: Elsevier, 183-257.

Ménard, Claude (2017), 'What Approach to Property Rights?' Journal of Institutional Economics, published online. DOI: 10.1017/S1744137417000145. 
Merrill, Thomas W., and Henry E. Smith (2000), 'Optimal Standardization in the Law of Property: The Numerus Clausus Principle’, Yale Law Journal 110(1), 1-70.

Merrill, Thomas W., and Henry E. Smith (2011), 'Making Coasean Property More Coasean', Journal of Law and Economics 54(4), S77-S104.

Ostrom, Elinor (1990), Governing the Commons: The Evolution of Institutions for Collective Action, Cambridge: Cambridge University Press.

Smith, Henry E. (2011), 'Standardization in Property Law', in Kenneth Ayotte and Henry E. Smith, eds., Research Handbook on the Economics of Property Law, Cheltenham, UK and Northampton, MA, USA: Edward Elgar, 148-73.

Smith, Henry (2017) 'Property as Complex Interaction', Journal of Institutional Economics, published online. DOI: 10.1017/S1744137417000157. 